\title{
Vulnerability: Too Vague and Too Broad?
}

\author{
DORIS SCHROEDER and EUGENIJUS GEFENAS
}

\section{Introduction}

Imagine you are walking down a city street. It is windy and raining. Amidst the bustle you see a young woman. She sits under a railway bridge, hardly protected from the rain and holds a woolen hat containing a small number of coins. You can see that she trembles from the cold. Or imagine seeing an old woman walking in the street at dusk, clutching her bag with one hand and a walking stick with the other. A group of male youths walk behind her without overtaking, drunk and in the mood for mischief. It doesn't need an academic to say what vulnerability is. We can all see it, much more often than we care to.

Vulnerability is an important concept in bioethics because vulnerable groups are prone to exploitation in medical research, that is, they are easily taken unfair advantage of to serve another's interests. ${ }^{1}$ As such exploitation is morally wrong, ${ }^{2}$ all major international research guidelines demand measures to protect the vulnerable. It is surprising, then, that such an important concept should still face two major challenges in the early 21st century.

First, it has been argued that the concept of vulnerability remains vague ${ }^{3}$ and even that the "definition of vulnerability for the purposes of healthcare and research with human participants is ... an unanswered question. ${ }^{\prime 4}$ Second, it has been argued that the categories of vulnerable populations have been expanded so widely that almost everybody is included. As a result, the special protection reserved for genuinely vulnerable populations is being lost. ${ }^{5}$

This paper tries to help remedy the situation in two ways: first, by outlining a definition of vulnerability in response to the "unanswered question," namely, how vulnerability can be defined meaningfully within the research context, and second, by arguing that vulnerability assessments need to take closer account of identifiable markers for significant harms as opposed to proclaiming universal classifications.

\section{Vulnerability Definition: The Common Sense View}

In attempting to provide a meaningful definition of vulnerability, we proceed from a commonsense position before moving into research ethics. We thereby hope to achieve broader understanding and consensus among the many groups

This paper was prepared as part of GenBenefit, a research project funded by the European Community's Sixth Framework Programme, but reflects only the authors' views. We are grateful to the members of the GenBenefit Group and Armin Schmidt for comments on an earlier draft. 
who are involved in protecting vulnerable individuals (e.g., healthcare personnel, lawyers, and policymakers).

Defining vulnerability can be likened to the efforts of six blind men describing an elephant. ${ }^{6}$ In this South Asian legend, six blind men touch different parts of an elephant, the tusk, the trunk, the ear, the tail, and so forth. And when they try to describe the entity, they cannot agree. The moral of the story is that, depending on one's perspective, one may only be able to describe half-truths. So, what could it mean to be vulnerable? ${ }^{7}$

According to the New Oxford Dictionary of English, to be vulnerable means "to be exposed to the possibility of being attacked or harmed, either physically or emotionally." As synonyms for vulnerable, the thesaurus offers "defenseless, liable, imperfect, unprepared, frail, susceptible, weak, helpless, open to, exposed, in danger, at risk." Due to its Latin origin (vulnerare = to wound), many European languages use the same term (e.g., French, vulnérable, Italian, vulnerabile). Germanic languages, by contrast, express the meaning directly. For instance, verletzlich and verwundbar could be translated literally as "injurable" or "woundable." The commonsense definition of vulnerability is therefore as follows:

Dictionary Definition of Vulnerability

To be vulnerable means to be exposed to the possibility of being attacked or harmed, either physically or emotionally.

\section{Vulnerability Definition in Research Ethics}

The generic dictionary definition stands in marked contrast to a definition frequently used within international research ethics. The Council for International Organizations of Medical Science (CIOMS) notes on vulnerability as follows:
"Vulnerability" refers to a substantial incapacity to protect one's own interests owing to such impediments as lack of capability to give informed consent, lack of alternative means of obtaining medical care, . . or being a junior or subordinate member of a hierarchical group. ${ }^{8}$

In a later section, CIOMS clarifies that those with a substantial incapacity to protect their own interests are likely to lack power, intelligence, education, resources, or strength. Whereas the dictionary definition focuses on external factors, namely, the danger of being attacked, the CIOMS definition focuses on internal factors, namely, the inability to protect oneself. We argue in the following that a combination of both is required. But first, the short version of the CIOMS vulnerability definition is as follows:

CIOMS Definition of Vulnerability

To be vulnerable means to be substantially incapable of protecting one's own interests. 


\section{Vulnerability Definition: Combining Common Sense and Research Ethics}

In the Leviathan Thomas Hobbes (1588-1679) famously describes human life outside the protection of law as "solitary, poor, nasty, brutish, and short."9 Hobbes reasons that the weakest human being has enough strength to kill the strongest, either through "the use of secret machination or by confederacy with others." ${ }^{10}$ As a result, Hobbes claims that we are all exposed to the possibility of being attacked or harmed, even violently killed, unless we are being protected. Yet it would be unreasonable to maintain that all human beings are exposed to the possibility of harm to the same degree. For instance, this paper is written as part of a European-funded research project with partners and advisors from around the world. However, as shown in Table 1, looking at our statistical chances of having been killed at a young age (10-29), we see that they vary enormously.

These statistics show that an Australian youth is twice as likely to be violently killed than his or her German equivalent, yet almost 10 times (!!) less likely than his or her counterpart in Mexico. In this regard, youths in Mexico are most exposed to the possibility of death by homicide among the countries listed. Because exposure to the possibility of harm equals vulnerability according to the dictionary definition, can one say that youth in Mexico are most vulnerable to homicide (of the countries listed)? Yes one could. However, using the term vulnerability in this sense aligns it too closely with danger and thereby veils another element, namely, an inability to protect oneself as outlined by the CIOMS definition.

Let us explain the binary composition of vulnerability with reference to malaria. Human beings are not invincible; we all suffer from harm during our lives. As bioethicist Nancy Jecker notes: "All persons are made of 'flesh' not steel."11 One such potential harm is the bite from a malaria-carrying mosquito and the subsequent exposure to the malaria parasite. We are all fragile in the sense that it would be better for our health not to be exposed to the parasite. However, as Northern and Eastern Europeans, we, the authors, are not exposed to the possibility of contracting the disease, unless we travel. If we stay in our countries of birth, our risk of contracting malaria is zero (point 1: exposure to potential harm, i.e., danger). Let us assume, however, that we do travel. Because we understand the options for malaria prevention and have the means to access or

Table 1. Homicide Rates among Youths, Aged 10-29 Years, for Most Recent Year Available

Deaths per 100,000 population

$\begin{array}{lr}\text { France } & 0.6 \\ \text { Germany } & 0.8 \\ \text { Greece } & 0.9 \\ \text { United Kingdom } & 0.9 \\ \text { Italy } & 1.4 \\ \text { Australia } & 1.6 \\ \text { Lithuania } & 5.4 \\ \text { Philippines } & 12.2 \\ \text { Mexico } & 15.3\end{array}$

No data available from Africa. Source: World Health Organization. World Report on Violence and Health, Geneva: World Health Organization; 2002:28f. 
pay for them, we are fortunate, as we can protect ourselves from malaria (point 2: protection possibilities). Others are not so fortunate. A definition of vulnerability needs to combine the above two elements; the fragility of the human condition that exposes us all to the possibility of harm and the potential inability to protect ourselves. Importantly, the distinction is also relevant to policymakers, who can aim at reducing exposure to harm (e.g., eradicate the malaria parasite) or improving people's protective capacity (e.g., supply malaria nets).

This means that our first draft definition of being vulnerable could be as follows:

To be vulnerable means to be exposed to the possibility of harm while being substantially unable to protect oneself.

This definition combines an internal and an external element. First, to be vulnerable one has to be exposed to the possibility of harm, that is, danger (external element of vulnerability). It does not make sense to say that "the inhabitants of Cologne are vulnerable to malaria." A genuine danger is required for vulnerability to materialize. Second, to be vulnerable one has to be substantially unable to protect oneself (internal element of vulnerability). Exposure to danger alone is not what makes a person vulnerable. For instance, even when somebody is set to assassinate another person, the intended victim might have means of protecting herself, which renders her invulnerable to the assassination attempt. She could be sitting in a bullet-proof car with a bullet-proof vest, having been warned that an assassination might take place. In this case, she would not be vulnerable because she is able to protect herself against the danger. Vulnerability requires both internal and external elements.

In the next step, the above definition needs to be refined by moving closer to the topic of research ethics and including reasons for one's potential incapacity to protect oneself. ${ }^{12}$ Bioethicists distinguish between intrinsic and contingent reasons why some subjects might be unable to protect themselves. For instance, children and the severely mentally ill are "incompetent to determine their own good. They are, therefore, intrinsically vulnerable to exploitation" within the research setting. ${ }^{13}$ It is simply impossible for them to give informed consent. They inherently lack the decisionmaking capacity to do so. One could say they lack the ability to protect themselves. By contrast, illiterate and destitute adults "are competent to exercise self-determination. . . . Yet political, social, or economic circumstances make them easily victimized. . . . They are, therefore, contingently vulnerable to exploitation"14 ${ }^{14}$ within the research setting. A person who is unable to protect herself because she cannot read and because she might enroll in a risky study as her only means to access healthcare would probably be able to protect herself if her social and economic circumstances changed. One could say she lacks the means to protect herself, leading to the following refined definition: ${ }^{15}$

To be vulnerable means to be exposed to the possibility of harm while substantially lacking ability and/or means to protect oneself.

An objection that could be made against our definition is the following. Does our external element (exposure to the possibility of harm) not equate with the fragility of the human condition? Are we not all exposed to the possibility of 
harm? Indeed, we are. In this regard the dictionary definition lacks precision when used in the research ethics context. Special protection should not be accorded to humankind as a whole, based on fragility, but to those who are at an identifiable risk of being exploited in medical research. A thus refined and final definition would therefore be the following:

\section{Our Definition of Vulnerability}

To be vulnerable means to face a significant probability of incurring an identifiable harm while substantially lacking ability and/or means to protect oneself.

Having developed a definition such as this one, will it now be easier to protect the vulnerable in the medical research context? This would be rather optimistic to proclaim. There are two main practical obstacles, which a concise definition cannot resolve. First, as we observed using the statistics on homicide rates among youths, exposure to the possibility of harm comes in degrees. Even though violent death could befall a teenager in a Bavarian village, it is much more likely to occur in a city in Mexico. Overemphasizing the danger of being a teenager could then lead to an unnecessary expansion of vulnerable groups, disregarding relative risks in favor of group categorizations. Second, although none of us are made of steel, as Jecker rightly noted, we are not all exposed to the same dangers. As pointed out earlier, in Cologne one does not need protection from the malaria parasite. Ideally, nominations of vulnerable groups should therefore stand in relation to identifiable, possible harms. We shall return to these two practical problems in the identification of vulnerable groups after introducing the second challenge for the concept of vulnerability.

\section{Too Broad a Concept?}

It has been argued that the categories of vulnerable populations have been expanded so widely that the special protection reserved for vulnerable populations is being lost. This criticism was raised with reference to the latest amendment of the World Medical Association's (WMA) Declaration of Helsinki. The Declaration does not define vulnerability but instead categorizes vulnerable groups very broadly in Article 8:

\footnotetext{
Some research populations are vulnerable and need special protection. The particular needs of the economically and medically disadvantaged must be recognized. Special attention is also required for those who cannot give or refuse consent for themselves, for those who may be subject to giving consent under duress, for those who will not benefit personally from the research and for those for whom the research is combined with care. ${ }^{16}$
}

The above guideline pronounces groups as vulnerable per se, irrespective of identifiable possible harms. If one looks at the above description of vulnerable populations, one can indeed wonder who is not vulnerable in medical research. As Forster, Emanuel, and Grady commented: 
The new declaration goes further [than the old one], making every conceivable person vulnerable, from patients with an illness, to those who cannot give consent, to healthy volunteers. ... The new declaration expands the category of vulnerability so broadly that it eliminates this category; ... . if everyone is vulnerable, no one is entitled to special protection. ${ }^{17}$

In a table compiled in 2008, Samia Hurst listed the following groups as vulnerable populations contained in international guidelines: racial minorities, the economically disadvantaged, the very sick, children, prisoners, pregnant women, fetuses, healthy volunteers, those with mental or behavioral disorders, junior members of hierarchical groups, elderly persons, those in nursing homes, people receiving welfare benefits, the unemployed, patients in emergency rooms, homeless persons, nomads, refugees, patients with incurable diseases, members of communities unfamiliar with modern medical concepts, individuals who are politically powerless, and those who take part in research while in clinical care. ${ }^{18}$

The above notes on our definition might contribute to explaining why vulnerable groups proliferate. It is difficult to determine exactly when a degree of vulnerability is part of the fragility of the human condition or when it is so pronounced that special protection mechanisms are required. In other words, when are our relative risks or our inability to protect ourselves significant enough to warrant protection? The unemployed in Sweden might be at a higher risk of exploitation than the employed in this country, but do they really require special protection mechanisms when involved in research? They already enjoy the benefits of a comprehensive, protective net spun by their state. What, then, is the significant probability of their incurring an identifiable harm through research? On the other hand, if people are unemployed in Zimbabwe, where such a welfare net does not exist, the possibility that they might enroll in exploitative research for meager benefits such as a health check or the provision of meals is indeed a concern. The two groups share one label, "unemployed," but one enjoys the benefit of state protection, which Hobbes celebrated, whereas the other does not. This is similar to the problem David Resnik has identified when arguing that categorically pronouncing an expanding number of groups as vulnerable can easily lead to false categorizations.

If one regards all research subjects in the developing world as vulnerable, then one should provide the same protections for a white, male, urban businessman from South Africa and a black, female villager from Ethiopia. . . . Treating all subjects in developing nations as vulnerable is like treating all women as vulnerable. ${ }^{19}$

The white urban businessman from South Africa does not face a significant probability of incurring an identifiable harm when enrolling in medical research. He has the literacy, knowledge, and income levels to protect himself against exploitation. But he is part of a category (developing country participant), which includes a large number of vulnerable individuals due to serious economic disadvantage.

False categorizations are not the only complication in the attempt to identify vulnerable individuals through the use of group categorizations. At the same time, we are not all exposed to the same dangers; neither does all research 
involve similar risks. Ideally, the protection of vulnerable groups should stand in relation to identifiable possible harms.

To give an example, we cannot list all possible identifiable harms that can befall subjects in research (we take harms to include violations of human rights to wellbeing, autonomy, and justice). But we can give reliable markers for the incurrence of identifiable harm within the research context. These are:

1) Unfavorable risk/benefit ratio

2) Breach of confidentiality or privacy

3) Invalid consent

4) Lack of access to the benefits of research.

An unfavorable risk/benefit ratio can impact directly a person's well-being (a terminally ill patient undergoing a painful procedure with minute chances of improvement). ${ }^{20} \mathrm{~A}$ breach of confidentiality or privacy can impact well-being (paternity suits, stigma) or autonomy. Invalid consent falls into the realm of autonomy (with insufficient information, a research participant may take part in research she opposes on principle) and also covers undue inducement. Lack of access to the benefits of research is a justice issue, which has been noted in redrafts of the Declaration of Helsinki (Art. 30). ${ }^{21}$ Those taking part in research must be assured of access to any successfully marketed products (post-trial obligations), which must be relevant to local health needs.

Let us look at two different studies to see the difficulty of pronouncing groups as vulnerable independent from the significant probability of incurring an identifiable harm. Our examples are both set in the area of vaccine research. On the one hand, we have healthy volunteers in the United Kingdom who are taking part in a clinical trial Phase I. On the other hand, we have Kenyan sex workers, taking part in the search for a candidate vaccine for HIV by providing access to blood samples for genetic research, which are used for health monitoring. Both groups are considered vulnerable according to the latest version of the Declaration of Helsinki (not benefiting personally from the research; economically disadvantaged). To avoid breaches of confidentiality, we assume that all data stored with regard to the participants will be made untraceable.

Let us look at our four markers for identifiable potential harms. For a healthy volunteer, to take part in a clinical trial Phase I to test a new AIDS vaccine involves an unfavorable risk/benefit ratio. By contrast, allowing access to blood samples, which were taken for health monitoring, poses no risk to well-being. We excluded the possibility of breaches of confidentiality in both cases. All research projects carry the risk of invalid consent. In our case, the healthy volunteers might not understand the risk they are taking and potentially illiterate Nairobi sex workers might suffer from the therapeutic misconception of assuming that the use of their blood samples will lead to health benefits for them. The chances that the UK participants will not have access to the fruits of medical research are almost zero, given the coverage of the National Health Service. On the other hand, the likelihood that the sex workers will not have access to a future HIV vaccine are very high, given that they are extremely poor and that post-trial obligations are currently not enforceable. Hence, both the healthy volunteers and the sex workers are vulnerable with regard to two identifiable markers for harm. The healthy volunteers could face an unfavorable risk/benefit ratio and invalid 
consent. The sex workers could encounter invalid consent and lack of access to the benefits of research.

Let us now reverse the studies and undertake the vaccine clinical trial Phase I on Kenyan sex workers and the genetic research on UK healthy volunteers. Through this reversal, the sex workers suddenly face three identifiable markers for harm (unfavorable risk/benefit ratio, invalid consent, lack of access to the benefits of research) whereas the healthy volunteers face only one (invalid consent).

We noted earlier that we are not all exposed to the same dangers; neither does all research involve similar risks. What the example shows is that some vulnerable groups face a significant probability of incurring more identifiable harms in the same study. In most cases, the additional identifiable marker for harm will be a justice concern, namely, that those who are taking part in research do not share in its potential benefits. Discussions about vulnerable populations should therefore note that some vulnerable groups can face the entire spectrum of identifiable markers for harm, whereas others do not. This leaves us with three challenges for future work:

1) How to address the justice concern within vulnerability discussions, which have for decades focused mostly on autonomy concerns. It is here that the topic of benefit sharing will gain importance.

2) How group specifications can be made more sensitive to individual circumstances to avoid false categorizations.

3) How to move forward with a harm-specific analysis of vulnerability should this help resolve the problem of false categorizations.

\section{Notes}

1. Macklin R. Double Standards in Medical Research in Developing Countries. Cambridge, UK: Cambridge University Press; 2004:101.

2. Macklin R. Bioethics, vulnerability and protection. Bioethics 2003;17(5-6):472-86, at 472 .

3. Kipnis K. Vulnerability in research subjects: A bioethical taxonomy. In: National Bioethics Advisory Commission, eds. Report on Ethical and Policy Issues in Research Involving Human Participants, Vol. II, 2001; available at http://www.onlineethics.diamax.com/cms/8087.aspx (last accessed 27 April 2008); Ruof MC. Vulnerability, vulnerable populations and policy. Kennedy Institute of Ethics Journal 2004;14(4):411-25; Levine C, Faden RR, Grady C, Hammerschmidt D, Eckenwiler L, Sugarman J. The limitations of "vulnerability" as a protection for human research participants. The American Journal of Bioethics 2004;4(3):44-9. Rogers AC. Vulnerability, health and health care. Journal of Advanced Nursing 1997;26:65-72; Shi L. The convergence of vulnerable characteristics and health insurance in the U.S. Social Science and Medicine 2001;53(4):519-29.

4. Hurst SA. Vulnerability in research and health care; Describing the elephant in the room? Bioethics 2008;22(4):191-202 at p. 192.

5. Forster H, Emanuel E, Grady C. The 2000 revision of the Declaration of Helsinki: A step forward or more confusion? The Lancet 2001;358(9291):1449-53.

6. See note 4, Hurst 2008:192.

7. This paper does not provide an overview of the most common definitions. This has been done excellently elsewhere. See note 4, Hurst 2008.

8. Council for International Organizations of Medical Science. International Ethical Guidelines for Biomedical Research Involving Human Subjects, 2002; available at http://www.cioms.ch/frame_guidelines_nov_ 2002.htm (last accessed 22 April 2008).

9. Hobbes T. Leviathan. London: Penguin; 1985[1651]:183.

10. See note 9, Hobbes 1985[1651]:186.

11. Jecker NS. Protecting the vulnerable. The American Journal of Bioethics 2004;4(3):60-2. 


\section{Vulnerability: Too Vague and Too Broad?}

12. It is interesting to note that the most recent definition in the academic literature by Samia Hurst, a medical doctor, focuses exclusively on our external element. "[V]ulnerability should be understood as an identifiably increased likelihood of incurring additional or greater wrong." See note 4, Hurst 2008:195.

13. Silvers A. Historical vulnerability and special scrutiny. The American Journal of Bioethics 2004;4(3): 56-7 at p. 56.

14. See note 13 , Silvers 2004:56.

15. We are excluding here the possibility that people could have the means and the ability to protect themselves, but choose not to, thereby making themselves vulnerable voluntarily.

16. The World Medical Association. Declaration of Helsinki. Ethical Principles for Medical Research Involving Human Subjects, adopted by the 18th WMA General Assembly, Helsinki, Finland, June 1964, latest revision by the WMA General Assembly, Tokyo, 2004; available at http://www.wma.net/e/ policy/b3.htm (last accessed 9 July 2008). The latest amendment was made by the 52nd WMA General Assembly, Edinburgh, Scotland, October 2000.

17. Forster H, Emanuel E, Grady C. The 2000 revision of the Declaration of Helsinki: A step forward or more confusion? The Lancet 2001;358(9291):1449-53.

18. See note 4, Hurst 2008:193.

19. Resnik DB. Research subjects in developing countries and vulnerability. The American Journal of Bioethics 2004;4(3):63-4.

20. The first points look at benefits in the narrow sense, excluding justice issues, which are covered by the fourth point.

21. See note 16, The World Medical Association 2004. 


\section{University Library}

\section{- M M I E R R A A gateway to Melbourne's research publications}

Minerva Access is the Institutional Repository of The University of Melbourne

Author/s:

Schroeder, D;Gefenas, E

Title:

Vulnerability: too vague and too broad?

Date:

2009-04

Citation:

Schroeder, D. \& Gefenas, E. (2009). Vulnerability: too vague and too broad?. Camb Q Healthc Ethics, 18 (2), pp.113-121. https://doi.org/10.1017/S0963180109090203.

Publication Status:

Published

Persistent Link:

http://hdl.handle.net/11343/33020 